\title{
Serum Levels of Thiol and Disulphide in Acute Intracerebral Haemorrhage
}

\author{
Hesna $B^{1 *}$, Sadiye $G^{2}$, Gonul V², Ozcan $E^{3}$, Murat \\ $\mathrm{A}^{3}$ and Orhan $\mathrm{D}^{2}$ \\ ${ }^{1}$ Department of Neurology, Ataturk Training and \\ Research Hospital, Turkey \\ ${ }^{2}$ Department of Neurology, Yildirim Beyazit University \\ Medical School, Turkey \\ ${ }^{3}$ Department of Clinical Biochemistry and Department of \\ Neurology, Yildirim Beyazit University Medical School, \\ Turkey \\ *Correspondling author: Hesna B, Department of \\ Neurology, Ataturk Training and Research Hospital, \\ Bilkent Yolu 3. Km. Çankaya, 06800 Ankara, Turkey
}

Received: January 31, 2017; Accepted: March 13, 2017; Published: March 17, 2017

\section{Introduction}

An intracerebral haemorrhage (ICH) is a subtype of stroke with high morbidity and mortality that accounts for about $15 \%$ of all deaths from stroke [1]. The most common sites of an ICH are cerebral hemispheres, basal ganglia, thalamus, brainstem (predominantly the pons) and cerebellum [2]. In an $\mathrm{ICH}$, the primary damage occurs within minutes to hours from the onset of bleeding and is primarily the result of mechanical damage associated with the mass effect. Secondary damage is the most part and attributable to the presence of intraparenchymal blood and may be dependent on the initial hematoma volume or ventricular volume [3]. It may occur through many parallel pathological pathways including [1] cytotoxicity of blood [2], hypermetabolism [3], excitotoxicity [4], spreading depression [5], oxidative stress and inflammation [1,4-6].

In recent years, there has been an effort to improve the understanding of the molecular pathophysiology of an ICH, as it has become apparent that significant morbidity and mortality result not only from the initial insult but also from secondary brain injury in the subacute period [1,3,7-9]. In an effort to evaluate and monitor this secondary brain injury numerous candidate biomarkers have been studied to determine whether they reflect or participate in the pathophysiologic mechanisms that occur in the period following the initial ICH. Serum biomarkers are proteins found in the serum, either by means of direct leakage from the site of pathology or as a result of the body's reaction to a pathophysiologic process [10]. In some cases the role of the biomarker in ICH pathophysiology is well understood while in other cases this relationship is less clear.

There is also a growing body of evidence demonstrating that an abnormal thiol-disulphide imbalance is involved in the pathogenesis of a variety of diseases [11-14]. Therefore a determination of the serum levels of thiol and disulphide can provide valuable information on various normal or abnormal biochemical processes. To the best of our knowledge there is no evidence about the role of the antioxidant activity of thiols in the ICH. The aim of our study was to determine whether there is a change in the serum levels of thiol and disulphide in acute ICH patients and whether there is a relationship between their thiol levels as well as the hematoma volumes.

\section{Materials and Methods}

Patients diagnosed with acute primary ICH between November 2014 and November 2015 was included in this study. Patients with a history of stroke, diabetes mellitus, progressive degenerative brain disease, cancer and ICH associated with vascular malformations, 
Table 1: Determination of the ICH Score. Glasgow coma score( GCS)

3-4

$5-12$

13-15

Intracerebral haemorrhage volume, $\mathrm{cm}^{3}$

$\geq 30$

$<30$

Intraventricular haemorrhage( IVH)

Yes

No

Infratentorial origin of $\mathrm{ICH}$

Yes

No

Age

$\geq 80$

$<80$

Total Score (0-6)

GCS score indicates GCS score on initial presentation; ICH and IVH volume on initial CT and presence of any IVH on initial CT.

anevrisms and trauma were excluded. Healthy individuals admitted to the neurology clinic because of headache and neck ache were selected for the control group.

The native thiol, disulphide and total thiol levels of the patients were examined by taking intravenous blood samples from the patients during the first 24 hours of the ICH. The blood thiol levels were examined using a spectrophotometric method with automatic measurements developed by Erel and Neselioglu [15]. The blood samples were collected into plain tubes after a fasting period of 12 hours then the serum was separated after centrifugation at $1500 \mathrm{~g}$ for 10 minutes and stored at $-80{ }^{\circ} \mathrm{C}$ until analysis. The blood samples (from calcium-EDTA tubes) were analyzed in an auto-analyser and the complete blood counts (CBCs) and differentials were determined from the peripheral venous blood samples obtained upon admission.

The reducible disulphide bonds were reduced first to free-form functional thiol groups. The unused reductant sodium borohydride was consumed and removed with formaldehyde and all of the thiol groups including the reduced and native ones were detected after reacting with DTNB (5, 5'-dithiobis-[2-nitrobenzoic] acid). Half of the difference between the total and native thiols provided the dynamic disulphide amount (-S-S) [15].

The calculation of the hematoma volumes in the brain tomography scans was performed using the region of interest (ROI) method. The periphery of the lesion area in each section was drawn by hand and the surface area of the section was calculated automatically in $\mathrm{mm}^{2}$ by Picture Archiving and Communication System (PACS) software which was installed on the computer. The areas were summed and the results were multiplied by the section thickness [16]. In addition ICH scores were recorded [17] (Table 1). Overall the relationships between the thiol-disulphide levels of the patients and hematoma volumes and hematoma scores were investigated.

Because of the ICH patients' consciousness state, informed consent was obtained from all patients relatives. The study protocol was performed according to the principles of the Declaration of Helsinki and was approved by the institutional review board.

\section{Statistical analysis}

The distribution of the variables including the age, native thiol, disulphide, total thiol levels, and hematoma volumes of the
Table 2: Demographic characteristics.

\begin{tabular}{|c|c|c|c|c|}
\hline & $\begin{array}{c}\text { Patient } \\
(\boldsymbol{n}=\mathbf{2 9})\end{array}$ & $\begin{array}{c}\text { Control } \\
(\boldsymbol{n}=\mathbf{2 8})\end{array}$ & Test statistic & $\boldsymbol{p}$ \\
\hline Age $[$ mean $\pm S D]$ & $68.00 \pm 13.44$ & $68.14 \pm 13.06$ & $t=0.041$ & 0.968 \\
\hline Gender $[n(\%)]$ & & & & \\
\hline Male & $23(79.3)$ & $21(75.0)$ & $X^{2}=0.005$ & 0.943 \\
\hline Female & $6(20.7)$ & $7(25.0)$ & & \\
\hline
\end{tabular}

Table 3: Clinical characteristics of patients.

\begin{tabular}{|l|c|}
\hline $\begin{array}{l}\text { ICH Score } \\
{[\text { median (IQR)] }}\end{array}$ & Patient \\
\hline min - max & $1.0(2.0)$ \\
\hline $\begin{array}{l}\text { Hematoma volume }\left(\mathrm{cm}^{3}\right) \\
{[\text { median }(\mathrm{IQR})]}\end{array}$ & $0.0-3.0$ \\
\hline min - max & $6.9(12.8)$ \\
\hline Localisation $[n(\%)]$ & $1.6-116.3$ \\
\hline basal ganglia & \\
\hline cerebellum & $16(55.2)$ \\
\hline lobar & $4(13.8)$ \\
\hline brainstem & $8(27.6)$ \\
\hline
\end{tabular}

patients was examined using the Shapiro-Wilks test. The mean \pm standard deviation values were given for those variables with normal distributions. In the presentation of the descriptive statistics of the variables with abnormal distribution, the median value (interquartile range [IQR]) was used. In addition the minimum and maximum values for each variable were specified and $\mathrm{n}(\%)$ was used for categorical variables as hematoma localisation.

Independent sample $t$ tests were applied for comparing the native thiol and total thiol levels in the groups. The Spearman's correlation coefficient and polyserial correlation coefficient was used for the evaluation of the relationship between the hematoma volumes, hematoma score and thiol levels.

IBM SPSS Statistics 21.0 (released 2012, IBM Corp.; IBM SPSS Statistics for Windows, Version 21.0. Armonk, NY) software and $\mathrm{R}$ package 'polycor' library was used for the statistical analyses and calculations, and the statistical significance level was accepted as $p<0.05$.

\section{Results}

29 patients with acute ICH (mean age 68.00 13.44 years, 23 males and 6 females) and 28 healthy controls (mean age $68.14 \pm 13.06$ years, 21 males and 7 females) were included to the study. There were no statistically significant differences between the patients in terms of age $(t=0.041, p=0.968)$ and gender $\left(\chi^{2}=0.005, p=0.943\right)$ (Table 2$)$.

The median of the ICH score was $1.0(\mathrm{IQR}=2.0)$. The median of the hematoma volume was $6.9 \mathrm{~cm}^{3}(\mathrm{IQR}=12.8)(\mathrm{min} / \mathrm{max}: 1.2-116.3)$. Hematoma localisation was on the basal ganglia in 16 (55.2\%) of the patients (Table 3). The median length of stay at hospital was 11 days $(\mathrm{IQR}=7)$.

For the hematoma group the median native thiol level was determined to be $347.00 \pm 84.79 \mu \mathrm{mol} / \mathrm{L}(\mathrm{min} / \mathrm{max}$ : $157.8 / 526.1)$ whereas it was $390.14 \pm 28.54 \mu \mathrm{mol} / \mathrm{L}(\min / \max : 323.50 / 460)$ in the control group. The median total thiol level in the hematoma group was 
Table 4: Comparison of thiol and disulphide levels.

\begin{tabular}{|c|c|c|c|c|}
\hline & $\begin{array}{c}\text { Patient } \\
(\text { mean } \pm \text { SD) }\end{array}$ & $\begin{array}{c}\text { Control } \\
(\text { mean } \pm \text { SD) }\end{array}$ & Test statistics & $\boldsymbol{p}$ \\
\hline $\begin{array}{c}\text { Native thiol, } \mu \mathrm{mol} / \mathrm{L} \\
(\text { mean } \pm \text { SD) }\end{array}$ & $347.00 \pm 84.79$ & $390.14 \pm 28.54$ & $t=2.486$ & 0.017 \\
\hline $\begin{array}{c}\text { Disulphide }, \mu \mathrm{mol} / \mathrm{L} \\
(\text { mean } \pm \mathrm{SD})\end{array}$ & $19.04 \pm 8.26$ & $19.63 \pm 5.40$ & $t=0.316$ & 0.753 \\
\hline $\begin{array}{c}\text { Total thiol, } \mu \mathrm{mol} / \mathrm{L} \\
(\text { mean } \pm \mathrm{SD})\end{array}$ & $385.08 \pm 89.25$ & $429.39 \pm 36.65$ & $t=2.467$ & 0.018 \\
\hline
\end{tabular}

Table 5: Correlation analysis.

\begin{tabular}{|l|c|c|}
\hline & \multicolumn{2}{|c|}{ Hematoma Volume } \\
\hline & Rho & $p$ \\
\hline ICH score & $0.651^{*}$ & $<0.001$ \\
\hline Native thiol & 0.126 & 0.514 \\
\hline Disulphide & 0.039 & 0.841 \\
\hline Total thiol & 0.171 & 0.375 \\
\hline "polyserial correlation coefficient & & \\
\hline
\end{tabular}

determined to be $385.08 \pm 89.25 \mu \mathrm{mol} / \mathrm{L}$ ( $\min / \max : 173.00 / 598.40)$ while it was $429.39 \pm 36.65 \mu \mathrm{mol} / \mathrm{L}(\min / \max : 362.80 / 495.20)$ in the control group.

In general the native thiol and total thiol levels of the hematoma group were found to be lower compared to those of the control group and a statistically significant difference was found between the native and total thiol levels of the hematoma and control groups, respectively ( $t=2.486, p=0.017$; and $t=2.467, p=0.018$ ). The median disulphide level of the hematoma group was $19.04 \pm .26 \mu \mathrm{mol} / \mathrm{L}(\mathrm{min} /$ max: $3.15 / 36.15)$, and it was $19.63 \pm 5.40 \mu \mathrm{mol} / \mathrm{L}(\min / \max : 7.9 / 28.7)$ in the control group; as such the disulphide levels were similar in the groups ( $t=0.316, p=0.753)$ (Table 4 and Figure 1$)$.

Positive correlation was determined between ICH scores and hematoma volumes (rho $=0.651, p<0.001$; Table 5 ). The relationship between hematoma volumes, hematoma localization and thiol levels and the association between individual GCS score, the presence of IVH, infratentorial origin, age and the level of thiols was not significant $(p>0.05)$.

\section{Discussion}

In an $\mathrm{ICH}$ the extravasated blood components (primarily erythrocytes and plasma proteins) and the damage-associated molecular patterns including nucleic acids, extracellular matrix components, proteins, lipid mediators, ATP and uric acid released from necrotic and damaged tissue, impose a strong cytotoxic, prooxidative and proinflammatory insult toward adjacent viable brain cells and could be seen as early as minutes after onset of the ICH. At this early stage the toxicity of extravasated blood plasma components including blood-derived coagulation factors, complement components, immunoglobulins and other bioactive molecules are proposed to act as contributors to $\mathrm{ICH}$-affected tissue damage $[1,4,18]$.

Glial fibrillary acidic protein, S100B, $\beta$-amyloid, matrix metalloproteinase 9, B-type natriuretic peptide, vascular adhesion protein-1, soluble fas, blood glucose level, cytokines (TNFa, IL6, IL-10 and IL-11), acute phase proteins (CRP), immune cells (peripheral leukocytes), glutamate, ferritin, low-density lipoprotein, D-dimer, fibrinogen, factor XIII, copeptin and heat shock protein 70 are studied as blood markers of ICH to understand the pathologic processes and their role on the mechanisms of brain damage and/ or recovery in an ICH. Predictors of 30 day-mortality and functional outcome have been studied in ICH also $[19,20]$ but to date however no blood biomarker of ICH has been studied sufficiently to find its way into clinical routine.

Thiol-disulphide balance plays a major role in antioxidant defence, detoxification, signal transmission management of enzyme activities and apoptosis [15]. Thiols are a class of organic compounds that contain a sulfhydryl group (-SH) which is composed of a hydrogen and a sulphur atom attached to a carbon atom [21]. It has been accepted that the - $\mathrm{SH}$ group in the thiols is protective against oxidative stress. The plasma thiol pool is formed largely by albumin and protein thiols and to a lesser extent by low-molecular-weight thiols such as cysteinylglycine, cysteine (Cys), homocysteine, glutathione and $\gamma$-glutamylcysteine [22]. Thiols can undergo oxidation reactions via oxidants to form disulphide bonds [23]. In addition the oxidation of Cys residues can lead to the reversible formation of mixed disulfides between low-molecular-mass thiols and protein thiol groups when oxidative stress increases. Those disulphide bonds can be reduced back to thiol groups thus maintaining thiol-disulphide balance [24]. Therefore determination of dynamic thiol-disulphide status in diseases in which oxidative stress plays a major role in pathogenesis is important. We hypothesized that there might be impaired serum levels of thiol and disulphide in ICH patients when compared to the controls.

To the best of our knowledge this is the first study to demonstrate that the levels of native thiol and total thiol are lower in patients with ICH as compared to healthy individuals. This condition shows that the level of oxidative stress is higher in patients with ICH when compared to that of healthy individuals. However there was no
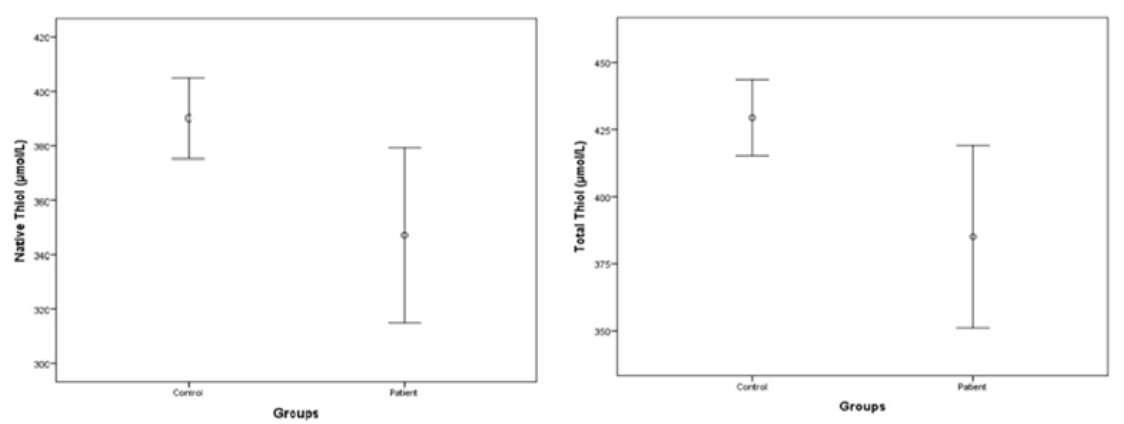

Figure 1: Thiol levels between ICH patients and control groups. 
difference between the groups in terms of the disulphide values. This shows that the balance between the thiol and disulphide levels was impaired. In addition, we found a positive correlation between the hematoma volumes and ICH score. But we didn't find any correlation between hematoma volumes and thiol levels. The major limitation of our study was the small number of the cases.

Since thiol is reducible in $\mathrm{ICH}$, any therapy that includes $\mathrm{SH}$ donors might diminish ICH-related neuronal damage. $\mathrm{N}$-acetylcysteine (NAC) is a thiol, a mucolytic, a neuroprotective agent, a precursor of L-cysteine and reduced GSH. It is a source of sulfhydryl groups in cells. NAC's antioxidant property of being a sulfhydryl donor may contribute to the regeneration of endothelium-derived relaxing factor and GSH [25]. Therefore substitution of thiol deficiency by NAC or alpha lipoic acid and correction of thiol-disulphide imbalance may be beneficial in managing treatment of the $\mathrm{ICH}$.

In conclusion, the present study has focused on the relation between thiol and disulphide in ICH patients. The findings might indicate that thiol might have an impact in the pathogenesis of an ICH. Serum levels of thiol and disulphide may be used in those patients with an ICH. This is because the levels are readily available, easily calculated, relatively cheap and automated, with the possibility of an optional manual spectrophotometric assay.

\section{Acknowledgement}

HB wrote the design of the study, collected the data and wrote the manuscript. OE and MA analyzed the results and made important contributions for the article. SG, GV and OD revised the manuscript. The biochemical analysis of this study was performed at the biochemistry lab of Ataturk Training and Research Hospital. The authors would like to thank OE's assistants. The statistical evaluation was made at the Department of Biostatistics, Yildirim Beyazit University.

\section{Ethical Standard}

The authors assert that all procedures contributing to this work comply with the ethical standards of the relevant national and institutional committees on human experimentation and with the Helsinki Declaration of 1975 as revised in 2008. Ethical approval of the study was granted by the Ethics Committee. Informed consent was obtained from all patients relatives.

\section{References}

1. Xi G, Keep RF, Hoff JT. Mechanisms of brain injury after intracerebral haemorrhage. Lancet Neurol. 2006; 5: 53-63.

2. Qureshi Al, Tuhrim S, Broderick JP, Batjer HH, Hondo H, Hanley DF Spontaneous intracerebral hemorrhage. N Engl J Med. 2001; 344: 14501460.

3. Qureshi Al, Mendelow AD, Hanley DF. Intracerebral haemorrhage. Lancet. 2009; 373: 1632-1644

4. Wagner KR, Sharp FR, Ardizzone TD, Lu A, Clark JF. Heme and iron metabolism: role in cerebral hemorrhage. J Cereb Blood Flow Metab. 2003; 23: 629-652.

5. Ardizzone TD, Lu A, Wagner KR, Tang Y, Ran R, Sharp FR. Glutamate receptor blockade attenuates glucose hypermetabolism in perihematomal brain after experimental intracerebral hemorrhage in rat. Stroke 2004; 35: 2587-2591.

6. Qureshi Al, Ali Z, Suri MF, Shuaib A, Baker G, Todd K, et.al. Extracellular glutamate and other amino acids in experimental intracerebral hemorrhage: an in vivo micro dialysis study. Crit Care Med. 2003; 31: 1482-1489.

7. Ducruet AF, Zacharia BE, Hickman ZL, Grobelny BT, Yeh ML, Sosunov $\mathrm{SA}$, et al. The complement cascade as a therapeutic target in intracerebral hemorrhage. Exp Neurol. 2009; 219: 398-403.

8. Lapchak PA, Araujo DM. Advances in hemorrhagic stroke therapy: conventional and novel approaches. Expert Opin Emerg Drugs 2007; 12: 389-406.

9. Selim M. Deferoxamine mesylate: a new hope for intracerebral hemorrhage: from bench to clinical trials. Stroke. 2009; 40: S90-S91.

10. Maas MB, Furie KL. Molecular biomarkers in stroke diagnosis and prognosis. Biomark Med. 2009; 3: 363-383.

11. Matteucci E, Giampietro O. Thiol signalling network with an eye to diabetes. Molecules. 2010; 15: 8890-8903.

12. Go YM, Jones DP. Cysteine/cystine redox signaling in cardiovascular disease. Free Radic Biol Med. 2011; 50: 495-509.

13. Kundi $H$, Ates I, Kiziltunc E, Cetin M, Cicekcioglu $H$, Neselioglu S, et al. A novel oxidative stress marker in acute myocardial infarction; thiol/disulphide homeostasis. Am J Emerg Med. 2015; 33:1567-1571.

14. Ates I, Kaplan M, Yuksel M, Mese D, Alisik M, Erel Ö, et al. Determination of thiol/disulphide homeostasis in type 1 diabetes mellitus and the factors associated with thiol oxidation. Endocrine 2016; 51: 47-51.

15. Erel O, and Neselioglu. A novel and automated assay for thiol/disulphide homeostasis. Clin Biochem. 2014; 47:326-32.

16. Zimmerman RD, Maldjian JA, Brun NC, Horvathd B, Skolnick BE. Radiologic estimation of hematoma volume in intracerebral hemorrhage trial by CT scan. AJNR Am J Neuroradiol. 2006; 27: 666-670.

17. Hemphill JC, Bonovich DC, Besmertis L, Manley GT, Johnston SC. The ICH score: a simple, reliable grading scale for intracerebral hemorrhage. Stroke. 2001; 32: 891-897.

18. Wang J, Doré S. Inflammation after intracerebral hemorrhage. J Cereb Blood Flow Metab. 2007; 27: 894-908.

19. Broderick JP, Brott TG, Duldner JE, Tomsick T, Huster G. Volume of intracerebral hemorrhage. A powerful and easy-to-use predictor of 30-day mortality. Stroke. 1993; 24: 987-993.

20. Szepesi R, Széll IK, Hortobágyi T, Kardos L, Nagy K, Lánczi LI, et.al. New prognostic score for the prediction of 30-day outcome in spontaneous supratentorial cerebral haemorrhage. Biomed Res Int. 2015; 2015: 961085.

21. Sen CK, Packer L. Thiol homeostasis and supplements in physical exercise. Am J Clin Nutr. 2000; 72: 653S-69S.

22. Turell L, Radi R, Alvarez B. The thiol pool in human plasma: the central contribution of albumin to redox processes. Free Radic Biol Med. 2013; 65: 244-253.

23. Cremers $\mathrm{CM}$, Jakob U. Oxidant sensing by reversible disulfide bond formation. J Biol Chem. 2013; 288: 26489-26496.

24. Jones DP, Liang Y. Measuring the poise of thiol/disulfide couples in vivo. Free Radic Biol Med. 2009; 47: 1329-1338.

25. Aruoma OI, Halliwell B, Hoey BM, Butler J. The antioxidant action of $\mathrm{N}$-acetylcysteine: its reaction with hydrogen peroxide, hydroxyl radical, superoxide, and hypochlorous acid. Free Radical Biol. Med. 1989; 6: 593597.
Austin J Cerebrovasc Dis \& Stroke - Volume 4 Issue 2 - 2017 ISSN : 2381-9103 | www.austinpublishing group.com Hesna et al. (C) All rights are reserved
Citation: Hesna B, Sadiye G, Gonul V, Ozcan E, Murat A and Orhan D. Serum Levels of Thiol and Disulphide in Acute Intracerebral Haemorrhage. Austin J Cerebrovasc Dis \& Stroke. 2017; 4(2): 1055. 